\title{
APPLICATION OF THE MIXED MONOTONE OPERATOR METHOD TO FRACTIONAL BOUNDARY VALUE PROBLEMS
}

\author{
John R. GRAEF, LingJU Kong And QINGKAI KonG
}

Abstract. The authors use the mixed monotone operator method to study the fractional boundary value problem

$$
\begin{gathered}
-D_{0^{+}}^{v} u(t)=\lambda f(t, u), t \in(0,1), \\
u^{(j)}(0)=0, j=0, \ldots, n-2, \quad\left[D_{0^{+}}^{\alpha} u(t)\right]_{t=1}=0 .
\end{gathered}
$$

Here, $m \geqslant 1$ and $n \geqslant 3$ are integers, $n-1<v \leqslant n, 1 \leqslant \alpha \leqslant n-2, u(t)=\left(u_{1}(t), \ldots, u_{m}(t)\right)^{T}$, $\lambda=\left(\lambda_{1}, \ldots, \lambda_{m}\right), \lambda f(t, u)=\left(\lambda_{1} f_{1}(t, u), \ldots, \lambda_{m} f_{m}(t, u)\right)^{T}$, and $D_{0+}^{v}$ is the Riemann-Liouville fractional derivative of order $v$. Existence, uniqueness, and dependence of positive solutions on the parameter $\lambda$ are discussed. An application to a special problem is also presented.

Mathematics subject classification (2010): Primary 34B15; secondary 34B18.

Keywords and phrases: Fractional boundary value problems, uniqueness, dependence on a parameter, mixed monotone operator method.

\section{REFERENCES}

[1] R. P. Agarwal, D. O'Regan, And S. Stanek, Positive solutions for Dirichlet problems of singular nonlinear fractional differential equations, J. Math. Anal. Appl. 371 (2010), 57-68.

[2] B. Ahmad AND S. Sivas Undaram, On four-point nonlocal boundary value problems of nonlinear integro-differential equations of fractional order, Appl. Math. Comput. 217 (2010), 480-487.

[3] Z. BAI AND H. LÜ, Positive solutions for boundary value problem of nonlinear fractional differential equations, J. Math. Anal. Appl. 311 (2005), 495-505.

[4] A. Dogan And J. R. GRAef, And L. Kong, Higher order singular multi-point boundary value problems on time scales, Proc. Edinburgh Math. Soc., to appear.

[5] M. El-Shahed AND J. J. NiETo, Nontrivial solutions for a nonlinear multi-point boundary value problem of fractional order, Comput. Math. Appl. 59 (2010), 3438-3443.

[6] C. S. GoODRICH, Existence of a positive solution to a class of fractional differential equations, Appl. Math. Lett. 23 (2010), 1050-1055.

[7] J. R. GRAEF AND L. KONG, Uniqueness and parameter dependence of positive solutions of third order boundary value problems with $p$-Laplacian, submitted for publication.

[8] D. GuO, Existence and uniqueness of positive fixed point for mixed monotone operators and applications, Appl. Anal. 46 (1992), 91-100.

[9] D. GUO AND V. LAKSHMiKAntham, Coupled fixed points of nonlinear operators with applications, Nonlinear Anal. 11 (1987), 623-632.

[10] A. A. Kilbas, H. M. Srivastava, And J. J. Trujillo, Theory and Applications of Fractional Differential Equations, Elsevier, Boston, 2006.

[11] L. Kong, Second order singular boundary value problems with integral boundary conditions, Nonlinear Anal. 72 (2010), 2628-2638

[12] X. LiAn AND Y. LI, Fixed point theorems for a class of mixed monotone operators with applications, Nonlinear Anal. 67 (2007), 2752-2762.

[13] Z. LIANG, L. ZHANG, AND S. Li, Fixed point theorems for a class of mixed monotone operators, Z. Anal. Anwend. 22 (2003), 529-542.

[14] I. Podlubny, Fractional Differential Equations, Academic Press, New York, 1999. 
[15] Z. WeI, W. Dong, AND J. Che, Periodic boundary value problems for fractional differential equations involving a Riemann-Liouville fractional derivative, Nonlinear Anal. 73 (2010), 3232-3238.

[16] Y. WU, New fixed point theorems and applications of mixed monotone operator, J. Math. Anal. Appl. 341 (2008), 883-893.

[17] Z. ZHANG AND K. WANG, On fixed point theorems of mixed monotone operators and applications, Nonlinear Anal. 70 (2009), 3279-3284.

[18] Z. ZHAO, Existence and uniqueness of fixed points for some mixed monotone operators, Nonlinear Anal. 73 (2010), 1481-1490. 